\title{
Gray zone: mortality profile of newborns at the limit of viability
}

Werther Brunow de Carvalho'

(iD) Felipe Yu Matsushita ${ }^{2}$

D Vera Lucia Jornada Krebs ${ }^{3}$

\author{
1. Médico em Cuidados Intensivos Pediátricos, Professor Pleno de Pediatria, Universidade de São Paulo, \\ Faculdade de Medicina, Departamento de Pediatria; São Paulo, SP, Brasil \\ 2. Pediatra, Universidade de São Paulo, Faculdade de Medicina, Departamento de Pediatria; São Paulo, SP, Brasil \\ 3. Pediatra, Professor Assistente, Ph.D., Universidade de São Paulo, Faculdade de Medicina, Departamento de Pediatria; São Paulo, SP, Brasil
}

The discussion about extreme prematurity and the limits of human viability currently constitutes an important theme with great relevance, with an imperative need to implement new clinical strategies for this population.

In recent years, some publications have shown that medical management varies based on local legislation, resources, and dilemmas relating to the interruption or non-introduction of invasive treatment measures ${ }^{1,2,3}$

Gestational age is considered the best feature in estimating the survival of these newborns, but other variables play an important role in the prognosis. In the United States, a consensus obtained by several medical entities, including the American Academy of Pediatrics ${ }^{4}$, was the definition of a peri-viable birth as a birth that occurs between $20^{0 / 7}$ and $25^{6 / 7}$ weeks. Upon analyzing the mean of these gestational ages, survival ranged from $0 \%$ to more than 50\%. The authors pointed out that gestational age and fetal weight are related to other variables, such as gender, multiple gestations, antenatal treatment with steroids, antibiotics, or neuroprotectors. Until more accurate models of neonatal prognosis are developed, gestational age remains the main predictor for guiding the conduct in the limit of fetal viability ${ }^{4,5}$. The interval between $23^{0 / 7}$ and $24^{6 / 7}$ weeks is considered the "gray zone", in which recommendations suggest individual neonatal resuscitation according to the parents' wishes ${ }^{5}$.

In neonates with a gestational age younger than 25 weeks, there is insufficient evidence to determine the prognostic factors of survival at birth or within the first 30 days of life. Variables such as gestational age accuracy, presence or absence of chorioamnionitis, and level of care complexity in neonatal ICU are considered $^{6,7}$.

In the latest published research on the topic, a national study in Korea ${ }^{9}$ the authors analyzed the variation of mortality according to age and causes of death 
in 621 newborns with gestational age of 23 and 24 weeks, dividing the patients into two groups, according to the mortality rate: group one, with mortality less than $50 \%$ and group two, with mortality equal to or greater than $50 \%$ of live births with borderline gestational age. The authors highlight the lower mortality in group one but do not describe the observed differences in the care structure between the two.

The Hospital das Clínicas of the Faculty of Medicine of the University of São Paulo, Brasil, is a national referral center for pregnant women at risk and intensive neonatal treatment at the quaternary level. Among 9476 live births in the period from 2012 to 2017 , there were 28 newborns admitted to the neonatal ICU with gestational age between $23^{0 / 7}$ and $24^{6 / 7}$ weeks. The mortality rate in these neonates was $85.7 \%$ in the postnatal age after 28 days of life, with only four survivors. The majority of deaths (60\%) occurred before seven days of life, with a predominance of early neonatal mortality. ${ }^{8}$

The main cause of death was infection, with a relevant role of maternal chorioamnionitis

There was a survival rate similar to group 2 from the study of Park et $\mathrm{al}^{9}(14.3 \%$ ), with comparable Apgar values, presence of chorioamnionitis and low body temperature at admission to the neonatal intensive care unit. In the article by Park et $\mathrm{al}^{9}$, the method of evaluation of gestational age was based only on the date of the last menstruation. Fetal ultrasound performed early, together with the date of the last menstruation, would be better indicated because of the greater precision, especially in a population where any variation causes a great impact on the management

Upon consideration of the above, some seminal questions arise: What would be the evolution of these patients in developing countries where there is a legal limitation to suspend treatment? How do developing countries approach preterm newborns in the gray area?

We suggest a national and a multinational multi-center study to analyze the clinical differences of extreme prematures with gestational age between 23 and 24 weeks. The centers would be analyzed according to their characteristics and the characteristics of the patients.

\section{Conflicts of interest}

The authors declare they have no conflict of interest

\section{Financial support}

none

\section{REFERENCES}

1. Wyllie J, Perlman JM, Kattwinkel J, WyckoffMH, Aziz K, Guinsburg R, Kim H-S, Liley HG, Mildenhall L, Simon WM, Szyld E, Tamura M, Velaphi S, on behalf of the Neonatal Resuscitation Chapter Collaborators. Part 7: Neonatal resuscitation: 2015 International Consensus on Cardiopulmonary Resuscitation and Emergency Cardiovascular Care Science With Treatment Recommendations. Resuscitation 2015;95:e169-e201.

2. Mercer BM. Periviable Birth and the Shifting Limit of Viability. Clin Perinatol 2017:44;283-6 http://dx.doi.org/10.1016/j.clp.2017.02.002

3. Rysavy MA, Li L, Bell EF, et al. Eunice Kennedy Shriver National Institute of Child Health and Human Development Neonatal Research Network. Between-hospital variation in treatment and outcomes in extremely preterm infants. N Engl J Med 2015;372:1801-11.

4. Raju TN, Mercer BM, Burchfield D|, et al. Periviable birth: executive summary of a joint workshop by the Eunice Kennedy Shriver National Institute of Child Health and Human Development, Society for Maternal-Fetal Medicine, American Academy of Pediatrics, and American College of Obstetricians and Gynecologists. Obstet Gynecol 2014;123:1083-96.
5. Pignotti MS, Donzelli G. Perinatal care at the threshold of viability: an international comparison of practical guidelines for the treatment of extremely preterm births. Pediatrics. 2008;121(1):e193-8.

6. Ishii N, Kono Y, Yonemoto N, et al, Neonatal Research Network, Japan. Outcomes of infants born at 22 and 23 Weeks' gestation. Pediatrics 2013;132:62-71.

7. Seaton SE et al. Babies born at the threshold of viability: chances in survival and workload over 20 year. Arch Dis Child Fetal Neonatal 2013; 98(1). F.15-20.

8. Matsushita FY, Krebs VLI, de Carvalho WB, Use of inotropes in a tertiary neonatal intensive care in Brazil: A critical analysis, presented to American Academy of Pediatrics National Conference \& Exhibition, Orlando, 2-6 November

9. Park JH, Chang YS, Sung S, Park WS, Network KN. Mortality Rate-Dependent Variations in the Timing and Causes of Death in Extremely Preterm Infants Born at 23-24 Weeks' Gestation. Pediatr Crit Care Med. 2019 Apr 2. [Epub ahead of print] 